\title{
MICROENCAPSULAÇÃO DE PROBIÓTICOS: INOVAÇÃO TECNOLÓGICA NA INDÚSTRIA DE ALIMENTOS
}

\author{
Microencapsulation of probiotics: technological innovation in the food industry \\ Caroline Posser Simeoni'; Mariana de Araújo Etchepare'; Cristiano Ragagnin de Menezes²; Leadir Martins \\ Fries $^{3}$; Maria Fernanda Cáceres Menezes'; Flávia Santi Stefanello'. \\ 'Universidade Federal de Santa Maria (UFSM) -Aluna do Programa de Pós - graduação de Ciência e Tecnologia dos Alimentos. \\ ${ }^{2}$ UFSM - Prof. Adjunto do departamento de Tecnologia e Ciência dos Alimentos \\ ${ }^{3}$ UFSM - Prof. Associada do departamento de Tecnologia e Ciência dos Alimentos
}

\begin{abstract}
Resumo
A crescente preocupação dos consumidores com uma alimentação saudável levou ao desenvolvimento de produtos funcionais que, além de sua função nutricional primordial, promovem saúde e bem estar ao consumidor. O interesse pela adição de microrganismos probióticos em vários alimentos vem crescendo, como forma de aumentar seus valores nutricionais e terapêuticos. Porém, o maior problema encontrado pelas indústrias na utilização de bactérias probióticas em alimentos está relacionado à manutenção e à viabilidade destas culturas. As culturas probióticas podem não sobreviver em número suficientemente alto quando submetidas a determinadas condições como, por exemplo, o armazenamento em baixas temperaturas e a passagem pelo trato gastrointestinal humano. Diante desse fato, diversas pesquisas têm focado na proteção e viabilidade das culturas probióticas durante a produção, armazenamento e passagem do produto probiótico pelo trato gastrintestinal. Os estudos têm mostrado que as culturas podem ser significativamente protegidas através da técnica de microencapsulação. Palavras-chaves: Microcápsulas, alimentos funcionais, bactérias, extrusão.
\end{abstract}

\begin{abstract}
The growing consumer concern about healthy eating led to the development of functional products, ie, that promotes health and well being of consumers beyond their primary nutritional function. The interest by the addition of probiotic microorganisms in various foods has been growing as a way to increase their nutritional and therapeutic values. However, the biggest problem faced by industries in the use of probiotic bacteria in foods is related to the maintenance and viability of these cultures. The probiotic cultures can not survive in sufficiently high number when subjected to certain conditions, for example, storage at low temperatures and the passage through the human gastrointestinal tract. Given this fact, many studies have focused on the protection and viability of probiotic cultures during production, storage and passage through the gastrointestinal tract probiotic product. Studies have shown that the cultures can be significantly protected by microencapsulation technique. Keywords: Microcapsules, functional foods, bacteria, extrusion.
\end{abstract}




\section{INTRODUÇÃO}

A produção de alimentos funcionais, contendo bactérias probióticas, é uma área que vem ganhando destaque na indústria alimentícia nos últimos anos. Os consumidores estão mais conscientes da relação entre boa alimentação e saúde, e por isso tem aumentado a procura por alimentos que, além de nutrir, proporcionem benefícios à saúde dos consumidores (GOMES et al., 2007; BURGAIN et al., 2011). Buscando satisfazer esse novo mercado, bactérias probióticas vêm sendo incorporadas em uma grande variedade de alimentos e bebidas que fazem parte de uma dieta normal como iogurtes, queijos, sorvetes, sucos, chocolates, cereais e produtos cárneos (ANAL; SINGH, 2007; MENEZES et al., 2013). Desse modo o consumidor pode desfrutar de refeições saborosas ao mesmo tempo em que promove efeitos benéficos à própria saúde (COMAN et al., 2012).

Microrganismos probióticos, quando empregados em alimentos com alegação de propriedade funcional, devem apresentar resistência às operações de processamento e viabilidade durante o período de armazenamento do produto (AKIN et al., 2007). Estes microrganismos devem estar presentes no produto em concentração significativa e, para que ocorra ação benéfica no intestino, devem ser capazes de sobreviver à acidez estomacal e aos sais biliares (CHAMPAGNE et al., 2011).

Para tanto, pesquisas têm demonstrado que as culturas probióticas podem ser significativamente protegidas através da técnica de microencapsulação. Essa técnica consiste no revestimento de microrganismos por uma matriz encapsulante, possibilitando a utilização destes em ampla variedade de produtos e em diversas formas. $\mathrm{Na}$ área de alimentos tem sido uma alternativa empregada para resolver os problemas de instabilidade e inviabilidade de probióticos (KAILASAPATHY, 2009).

$\mathrm{O}$ alginato de sódio é um dos polímeros mais empregados como material encapsulante, pois forma uma matriz altamente versátil, biocompatível e não tóxica para a proteção de componentes ativos, células e principalmente microrganismos probióticos, sensíveis ao calor, $\mathrm{pH}$, oxigênio, entre outros fatores em que os alimentos são expostos durante seu processamento e armazenamento (PASIN et al., 2012). Segundo Mortazavian et al. (2008) a quitosana apresenta uma boa capacidade de formação de película, sendo utilizada como revestimento exterior em cápsulas feitas com polímeros aniônicos como alginato.

Diversas técnicas podem ser utilizadas para microencapsulação de ingredientes alimentícios e a escolha do método depende: da aplicação que será dada à microcápsula, do tamanho, do mecanismo de liberação e propriedades físico-químicas, tanto do material ativo, quanto do agente encapsulante (JACKSON; LEE, 1991).

Essa revisão bibliográfica busca informar e esclarecer os conceitos, as técnicas e as aplicações da tecnologia de microencapsulação de probióticos na indústria alimentícia.

\section{PROBIÓTICOS E ALIMENTOS FUNCIO- NAIS}

O termo alimento funcional foi definido inicialmente no Japão, durante a década de 1980, como "alimento para uso específico de saúde". O conceito contemporâneo refere-se aos alimentos ou nutrientes cuja ingestão leva a importantes mudanças fisiológicas no organismo, isoladas ou distintas daquelas associadas ao seu papel nutricional (FDA, 2004). Neste segmento destacam-se alimentos com microrganismos probióticos, especialmente os produtos lácteos probióticos, que detêm imensa popularidade e representam a maior parcela do mercado mundial de alimentos funcionais (AGRAWAL, 2005; SIRÓ et al., 2008).

O termo probiótico já é bem conhecido e usado desde a década de 50, na época, Vergin (1954) sugeriu que o equilíbrio da flora intestinal pode ser perdido após o uso de antibióticos, todavia pode ser restaurado por uma dieta de probióticos, incluindo alimentos fermentados. Com o passar dos anos houve algumas modificações nesse conceito e hoje em dia os probióticos são definidos como microrganismos vivos que, quando administrados em quantidades adequadas, conferem benefícios à saúde do hospedeiro (FAO, 2002).

Um alimento vendido com alegações de trazer benefícios à saúde devido à adição de probióticos deve conter um número de células viáveis de culturas probióticas de, pelo menos, 106 a $107 \mathrm{UFC} / \mathrm{g}(\mathrm{FAO}, 2002)$ e recomenda-se uma dose de ingestão diária de 108 a 1010 UFC/dia (BRASIL, 2008; REID, 2008; KRASAEKOOP et al., 2003).

Segundo Dunne et al. (2001), os principais critérios para um microrganismo ser considerado probiótico são: apresentar resistência à acidez gástrica e aos sais biliares (o baixo $\mathrm{pH}$ gástrico é um dos primeiros mecanismos de defesa contra a ingestão de microrganismos, incluindo probióticos); 
capacidade de aderir nas células da mucosa intestinal para aumentar a persistência e multiplicação dos microrganismos no intestino (o que promove exclusão competitiva de patógenos potenciais da superfície intestinal); produzir substâncias antimicrobianas contra patógenos intestinais a fim de restaurar a composição da microflora; devem ser seguros em alimentos e durante o uso clínico, mesmo em indivíduos imunocomprometidos; capacidade de ser produzido em grande escala e de forma viável (também é importante que seja viável e ativo no produto que servirá de veículo); segurança aprovada para o consumo humano, através de meios científicos e experiências baseadas no consumo de alimentos por um grande número de consumidores; serem isolados do trato gastrintestinal humano, pois acredita-se que são mais seguros e mais efetivos na flora intestinal humana.

Os probióticos mais importantes são as bactérias ácido láticas, por desempenharem efeito benéfico conhecido no trato gastrintestinal. Lactococcus lactis, Enterococcus faecium e Bifidobacterium spp. são representantes dessa classe. Esses microrganismos são gram- positivos e geralmente anaeróbicos facultativos, com exceção do gênero Bifidobacterium, que são anaeróbicos estritos. Outros microrganismos como bactérias não ácido láticas, e até algumas leveduras como Saccharomyces cerevisiae e Saccharomyces boulardii, podem ser probióticas (ANAL; SINGH, 2007).

No Brasil, os probióticos atualmente regulamentados por legislação, para aplicação em alimentos com alegação de propriedades funcionais, são Lactobacillus acidophilus, Lactobacillus casei, Lactococcus lactis, Bifidobacterium bifidum, Bifidobacterium animallis, Bifidobacterium longum e Enterococcus faecium (BRASIL, 2008).

Muitos estudos clínicos têm demonstrado a eficácia terapêutica e profilática de probióticos específicos contra gastrenterite viral aguda, diarréia associada a antibióticos, infecção por Clostridium difficile e por Helicobacter pylori, doença intestinal inflamatória e síndrome do intestino irritado (GILL, 2003). Os efeitos dos probióticos são cepa-dependentes, desse modo, cada cepa proporciona diferentes benefícios para a saúde do consumidor (CHEN; CHEN, 2007). O mecanismo preciso, pelo qual os probióticos potencializam a defesa gastrintestinal do hospedeiro e conferem proteção, ainda não é completamente conhecido, mas acredita-se que tem ligação com a produção de nutrientes e co-fatores, competição com patógenos por sítios de ligação e estimulação da resposta imune (SAIER; MANSOUR, 2005).
Os produtos lácteos são os mais comumente utilizados como veículos de bactérias probióticas, com apelo de alimento funcional, no entanto vários fatores que afetam a viabilidade dos probióticos têm sido relatados nesses produtos, incluindo concentração de açúcares, proteínas e gorduras, valor de $\mathrm{pH}$, concentração de oxigênio, temperatura de armazenamento, interação com outros microrganismos contidos nos produtos e a atividade de água (CASTRO-CISLAGHI et al., 2012).

Para que um alimento possa carrear as células probióticas com segurança e viabilidade, assegurando a eficácia do produto funcional, vários fatores devem ser levados em consideração, tais como a seleção adequada da cultura probiótica, a concentração do inóculo, o estágio do processamento em que a cultura é adicionada, atributos físico-químicos e ingredientes do produto (COMAN et al., 2012). A viabilidade dos probióticos é de suma importância, eles devem chegar e permanecer vivos no sítio de ação para que possam desempenhar o seu papel na saúde dos consumidores (CHAMPAGNE et al., 2011). No entanto, trabalhos relatam que a sobrevivência de células probióticas livres nos alimentos é baixa (DE VOS et al., 2010), sendo necessária a existência de uma barreira física resistente às condições adversas do meio (KAILASAPATHY, 2009).

A administração oral dessas bactérias é outro fator que resulta em uma perda significativa de células viáveis devido à passagem pelo trato gastrintestinal, principalmente pela alta acidez estomacal e a concentração de sais biliares. Essa perda de viabilidade diminui a eficácia dos produtos funcionais (COOK et al., 2012). O microrganismo que se mostrar metabolicamente estável no produto e, ainda, sobreviver à passagem pelo trato digestivo com alta viabilidade poderá apresentar efeitos benéficos quando chagar ao intestino do hospedeiro (ANAL; SINGH, 2007).

\section{MICROENCAPSULAÇÃO}

Consiste em um processo mecânico ou físico-químico que imobiliza e protege os microrganismos em um material encapsulante, gerando partículas com diâmetro pequeno, de nanômetros a poucos milímetros, que são capazes de manter sua estrutura mesmo sob as condições adversas do meio, sendo dissolvidas e liberando o material encapsulado no sítio de ação adequado para exercer a função desejada. Por essas características, 
a tecnologia de microencapsulação está sendo pesquisada como forma de aumentar a viabilidade das células probióticas nos alimentos e no trato gastrintestinal (BORGOGNA et al., 2010).

Diferentes técnicas podem ser usadas na microencapsulação de probióticos e cada uma delas fornece microcápsulas com diferentes características. A viabilidade bacteriana no produto depende da sobrevivência do probiótico aos processos de microencapsulação, do tipo e da concentração do material de revestimento, do tamanho das partículas, do número de células bacterianas inicial e da cepa bacteriana (CHEN; CHEN, 2007). O tamanho das microcápsulas pode variar de microns até milímetros e parece influenciar na sobrevivência dos microrganismos. As características ideais para um probiótico microencapsulado apresentar-se seria na forma de um pó seco, de armazenamento fácil e de vida de prateleira longa ou, então, um gel úmido com estabilidade a longo prazo (COOK et al., 2012; BURGAIN et al., 2011).

De acordo com Cook et al., (2012), os méto- dos de microencapsulação de probióticos seguem três metodologias principais, que são: atomização ou spray drying, emulsificação e extrusão.

A técnica de spray drying tem como características a produção de grande quantidade de material, sendo uma alternativa economicamente viável. Os polímeros encapsulantes mais utilizados nessa técnica são a goma arábica e o amido, pelo fato que tendem a formar micropartículas esféricas durante o processo de secagem (DE VOS et al., 2010). Em contrapartida, há uma perda de viabilidade dos microrganismos bastante acentuada nesse processo, resultante da temperatura e da desidratação, utilizadas na técnica (SUNNY-ROBERTS; KNORR, 2009). Para aumentar a viabilidade bacteriana podem ser utilizados agentes termoprotetores como amido, fibra solúvel e trealose, que são adicionados no meio antes da secagem. Esse método é altamente reprodutível e apropriado para aplicações industriais (BURGIAN et al., 2011). Na Figura 1 está representado esquematicamente o processo de spray drying.

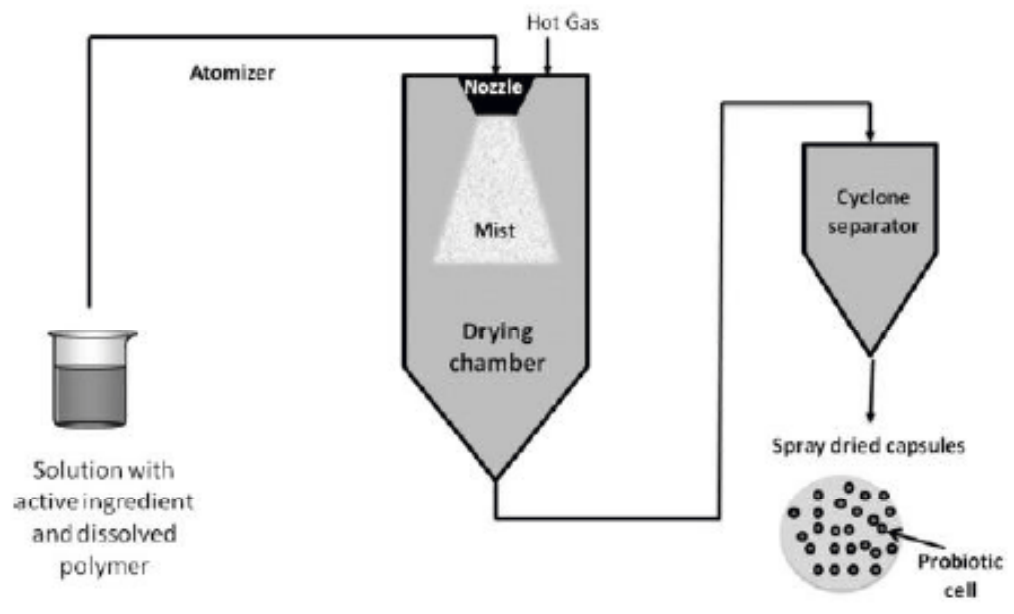

Figura 1- Representação esquemática do procedimento de spray drying.

Fonte: BURGIAN et al. (2011)

A emulsificação é um método químico para encapsular bactérias probióticas em hidrocolóides como alginato, carragena e pectina. $\mathrm{O}$ princípio dessa técnica é baseado na relação entre a fase descontínua (solução encapsulante com células probióticas) e a fase contínua (óleo). Para encapsulação em uma emulsão, um emulsificante e um surfactante são necessários, além de um agente solidificante (cloreto de cálcio) que é adicionado à emulsão. A mistura é homogeneizada para formar uma emulsão água em óleo. Formada a emulsão, o polímero solúvel em água deve ser insolubilizado para formar pequenas partículas de gel dentro da fase de óleo. As microcápsulas são recuperadas por filtração ou centrifugação. A técnica de emulsificação é de fácil realização e apresenta uma alta taxa de sobrevivência das células bacterianas. É possível obter cápsulas de diâmetro reduzido, no entanto, a principal desvantagem dessa técnica é que não há uma padronização no tamanho e formato das microcápsulas (CHEN; CHEN, 2007; KAILASAPATHY, 2009; DE VOS et al., 2010). Fatores como velocidade de agitação da emulsão, quantidade de agente solidificante usado e concentração do surfactante também têm um efeito sobre o tamanho das gotículas da fase dispersa, 
que, eventualmente, influenciam o tamanho das microcápsulas (SHAH; RAVULA, 2000). Na Figura 2 está representado o processo de microencapsulação por emulsificação.

A técnica de extrusão é um processo físico para encapsulação de probióticos em hidrocolóides, geralmente alginato, pectina e carragena. Tal técnica consiste em projetar esse material através de um bocal de alta pressão, que irá gotejar em uma solução contendo cloreto de cálcio $(\mathrm{CaCl})$, para que ocorra a solidificação por gelatinização iônica. Nesse processo, o cálcio difunde-se para o interior das gotas de alginato (LIU et al., 2002). A extrusão é um processo que não causa danos ás células bacterianas, conferindo maior viabilidade dos microrganismos encapsulados em comparação ao método de spray drying. É uma técnica simples e barata, mas possui a desvantagem de ser de difícil aplicação em grande escala industrial, devido à formação das microcápsulas ser muito lenta (KRASAEKOOP et al., 2003). Na Figura 3 está representado o processo de microencapsulação pelo método de extrusão.

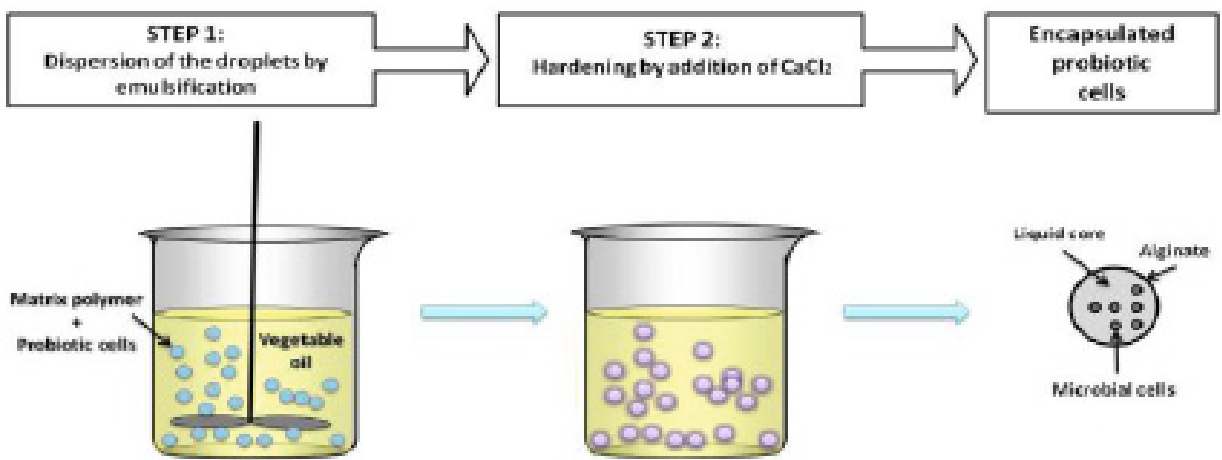

Figura 2- Representação esquemática do procedimento de emulsificação.

Fonte: BURGIAN et al. (2011).

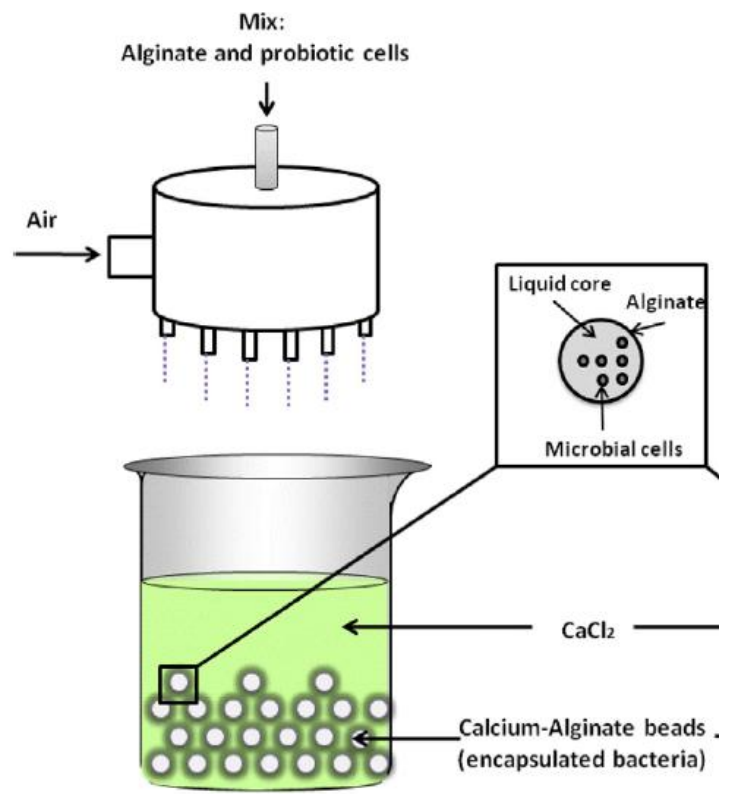

Figura 3- Representação esquemática do procedimento de extrusão.

Fonte: BURGIAN et al. (2011).

Um dos principais fatores que influencia a estabilidade do composto encapsulado é o tipo de agente encapsulante utilizado na microencapsulação. A escolha do agente se baseia nas características físicas e químicas do composto a ser encapsulado, moduláveis a ponto de produzir partículas com as características desejadas, com tamanho, estrutura, carga, permeabilidade 
e estabilidade adequadas para o tipo de aplicação pretendida (fármaco, aditivo alimentar, fragrância, pesticida) e no método de microencapsulação utilizado (SUAVE et al., 2006), além de apresentarem um mecanismo de liberação satisfatório, serem atóxicos e não possuírem reatividade com o material a ser encapsulado (FAVARO-TRINDADE, 2008).

$\mathrm{Na}$ indústria de alimentos, diversos polissacarídeos e proteínas podem ser utilizados na fabricação de microcápsulas. As matrizes encapsulantes mais utilizadas são alginato de cálcio, carragena, amido e amido resistente, quitosana, gelatina e proteínas (COOK et al., 2012; BURGAIN et al., 2011).

De acordo com Sheu e Marshal (1993), o alginato tem sido frequentemente usado para imobilização de bactérias ácido-láticas, pois possui propriedades de ser atóxico para as células encapsuladas, ser de baixo custo, formar facilmente uma matriz ao redor das células bacterianas e ser um aditivo aceito para alimentos (PREVOST; DIVIES, 1992). No entanto, a desvantagem desse polissacarídeo é a formação de poros na superfície das cápsulas, tornando-as sensíveis às condições ácidas do meio (MORTAZAVIAN et al., 2007). Para suprir esse problema, é possível recobrir as cápsulas com outros compostos poliméricos, a fim de garantir um maior efeito protetor aos microrganismos (KRASAEKOOPT et al., 2003).

A carragena é um polissacarídeo natural, extraído de algas marinhas, comumente utilizado como aditivo em alimentos. O processo de gelificação de k-carragena depende diretamente da mudança de temperatura. As microcápsulas são formadas através do gotejamento em solução composta com a mistura do polímero a ser utilizado e a solução de potássio, como $\mathrm{KCl}$. Porém, foi demonstrado que o $\mathrm{KCl}$ confere um efeito inibidor em algumas linhagens de microrganismos (AUDET et al., 1991).

Amido é um polissacarídeo formado por um grande número de glicoses unidas por ligações sacarídicas. Amido resistente é um tipo de amido que não é digerido no intestino delgado pelas enzimas pancreáticas, como amilase. Dessa maneira, ele chega íntegro ao cólon, só liberando as bactérias probióticas no intestino grosso (SAJILATA et al., 2006). Além disso, o amido resistente é um prebiótico funcional que poderá ser utilizado pelas bactérias probióticas no intestino grosso. $\mathrm{O}$ amido resistente também é uma superfície ideal para a aderência de células probióticas, o que pode aumentar a liberação de células probióticas metabolicamente ativas no intestino (MORTA-
ZAVIAN et al., 2007).

A quitosana é um polímero catiônico obtido a partir da quitina, que é extraída do exoesqueleto de crustáceos aquáticos ou, ainda, pode ser encontrada na parede celular de alguns fungos (GEORGE; ABRAHAM, 2006). Por ser biodegradável por bactérias do cólon, apresentar biocompatibilidade, hipoalergenicidade e propriedades mucoadesivas que otimizam a penetração de macromoléculas pelas barreiras intestinais, a quitosana tem sido bastante utilizada na microencapsulação, principalmente no revestimento das microcápsulas (AHN et al., 2002; KANMANI et al., 2011).

A gelatina é uma goma proteica que constitui um composto muito útil para a microencapsulação isolada ou associada com outros compostos. Possui propriedades gelificantes termorrevesíveis, que se gelifica quando é resfriada e se liquefaz quando é aquecida (HEIDEBACH et al., 2009). As proteínas têm se tornado uma boa escolha para a microencapsulação de probióticos. Comercialmente as proteínas mais utilizadas incluem a caseína, soroalbumina bovina e proteína de soja (COOK et al., 2012). As proteínas do leite são veículos naturais de células probióticas, devido às suas características físico-químicas e sua estrutura elas podem ser usadas como um meio de liberação. Essas proteínas possuem boa capacidade de gelatinização, que está sendo explorada na microencapsulação de probióticos (LIVNEY, 2010).

\section{ALIMENTOS COMO VEículo DE PROBI- ÓTICOS}

Os alimentos probióticos representam cerca de $65 \%$ do mercado mundial de alimentos funcionais (AGRAWAL, 2005) e segundo Nazzaro et al. (2011) este mercado continua expandindo. Os exemplos mais conhecidos de alimentos probióticos são leites fermentados e iogurtes, no entanto, outros derivados lácteos como queijos, sorvetes e sobremesas já estão sendo estudados (NAGPAL et al., 2007). Nos países desenvolvidos é crescente a popularidade dos alimentos funcionais contendo probióticos e isto se deve aos avanços nas pesquisas em desenvolvimento de novos produtos, que resultaram na incorporação de probióticos não só em produtos lácteos, mas também em bebidas, cereais, chocolates e, até mesmo, em produtos cárneos (MATTILA-SANDHOLM, 2002). A maioria dos produtos contendo probióticos protegidos é disponível em tabletes, cápsulas ou em forma de 
pó (BURGIAN et al., 2011).

A viabilidade destes microrganismos durante toda a vida de prateleira do produto aos quais forem adicionados representa um grande desafio à indústria de alimentos (DOUGLAS; SANDERS, 2008), uma vez que algumas culturas são extremamente sensíveis a fatores como meio ácido e oxigênio (KAILASAPATHY; CHIN, 2000). Justamente por apresentarem condições favoráveis, os produtos lácteos são os alimentos mais utilizados como veículos de probióticos (THAMER; PENNA, 2006). No entanto, alguns fatores que podem afetar a viabilidade dos probióticos têm sido relatados em produtos lácteos fermentados, queijos duros, cereais e sucos, como a acidez titulável, baixo valor de $\mathrm{pH}$ e peróxido de hidrogênio, a concentração de ácido láctico e acético (CASTRO-CISLAGHI et al., 2012). Alimentos com baixo valor nutritivo e reduzida atividade de água também apresentam condições desfavoráveis para a sobrevivência dos probióticos. Nesses alimentos, para que seja possível incorporar bactérias probióticas, é necessário utilizar tecnologias que protejam o microrganismo do meio externo e aumentem sua viabilidade no produto (OROSCO et al., 2012).

A viabilidade de células probióticas microencapsuladas, sob as mesmas condições, foi analisada em diferentes produtos e o resultado mostrou que todos os alimentos apresentaram resultados distintos quanto à sobrevivência dos microrganismos. No queijo cheddar e no sorvete a microencapsulação não é necessária para a sobrevivência das células probióticas no produto, no entanto no iogurte a microencapsulação se demonstrou importante (GODWARD; KAILASAPATHY, 2003 a b b c). O queijo cheddar é um veículo de probióticos melhor que o iogurte, pois as células bacterianas tem maior capacidade de resistir ao $\mathrm{pH}$ ácido do estômago quando veiculadas nesse alimento (SHARP et al., 2008).

A finalidade da microencapsulação de probióticos é proteger os microrganismos das condições adversas do meio, das baixas temperaturas de congelamento (SHEU; MARSHALL, 1993), do efeito bactericida do suco gástrico e outros meios ácidos (OLIVEIRA et al., 2007), além de aumentar a estabilidade e manter a viabilidade da cultura durante a estocagem do produto (KAILASAPATHY, 2009). A adição das microcápsulas não deve afetar as características sensoriais dos alimentos, por isso é recomendado que o diâmetro das microcápsulas seja menor que $100 \mu \mathrm{m}$.

\section{CONCLUSÕES}

A microencapsulação é uma tecnologia nova, na área de alimentos, que demonstra proteger as células probióticas no produto e durante a passagem pelo trato gastrintestinal. A liberação do probiótico ocorre no sítio de ação desejado, aumentando seu efeito e melhorando a saúde do consumidor. Muitos estudos estão sendo conduzidos nessa área e têm apresentado resultados promissores. Esforços no sentido de desenvolver microcápsulas de menor diâmetro e melhores propriedades devem ser intensificados. No entanto mais estudos são necessários no âmbito de empregar essa tecnologia em escala industrial e desenvolver produtos inovadores que possam atuar como veículos de probióticos.

\section{REFERÊNCIAS}

AGRAWAL, R. Probiotics: an emerging food supplement with health benefits. Food Biotechnology, v. 19, p. 227-46, 2005.

AHN, S. J. et al. Release of triamcinolone acitonide from mucoadhesive polymer composed of chitosan and poly in vitro. Biomaterials, v. 23, p. 1411-1416, 2002.

AKIN, M. B.; AKIN, M. S.; KIRMACI, Z. Effects of inulin and sugar levels on the viability of yogurt and probiotic bacteria and the physical and sensory characteristics in probiotic ice-cream. Food Chemistry, v. 104, p. 93-99, 2007.

ANAL, A. K.; SINGH, H. Recent advances in microencapsulation of probiotics for industrial applications and targeted delivery. Trends Food Science and Technology, v. 18, n. 5, p. 240-251,2007.

AUDET, P. et al. Effect of medium and temperature of storage onviability of LAB immobilized in k-carrageenan-locust bean gum gel beads. Biotechnology Techniques, v. 4, p. 307-312, 1991.

BORGOGNA, M. et al. Food microencapsulation of bioactive compounds: rheological and thermal characterisation of non-conventional gelling system. Food Chemistry, v. 122, n. 2, p. 416-423, 2010.

BRASIL. Lista de alegações de propriedade funcional aprovadas. Brasília, 2008. 
Disponível em: http://www.anvisa.gov.br/alimentos/ comissoes/tecno_lista_alega.htm. Acesso em: 06 de out. de 2013.

RGAIN, J. et al. Encapsulation of probiotic living cells: From laboratory scale to industrial applications. Journal of Food Engineering, v. 104, p. 467483, 2011.

CASTRO-CISLAGHI, F. P. et al. Bifidobacterium $\mathrm{Bb}-12$ microencapsulated by spray drying with whey: Survival under simulated gastrointestinal conditions, tolerance to $\mathrm{NaCl}$, and viability during storage. Journal of Food Engineering, v. 113, p. 186-193, 2012.

CHAMPAGNE, C. P. et al. Recommendations for the viability assessment of probiotics as concentrated cultures and in food matrices.International Journal of Food microbiology, v. 149, p. 185-193, 2011.

CHEN, M. J.; CHEN, K. N. Applications of probiotic encapsulation in dairy products. In: Lakkis, Jamileh M. (Ed.), Encapsulation and Controlled Release Technologies in Food Systems. Wiley-Blackwell, USA. P. 83-107, 2007.

COMAN, M. M. et al. Functional foods as carriers for $S Y N B I O \AA$, a probiotic bacteria combination. International Journal of Food Microbiology, v. 157, p. 346-352, 2012.

COOK, M. T. et al. Microencapsulation of probiotics for gastrointestinal delivery. Journal of Controlled Release, v. 162, n. 56-67, 2012.

DESAI, K. G. H.; PARK, H. J. Recent developments in microencapsulation of food ingredients. Drying Technology, v. 23, n. 7, p. 1361-1394, 2005.

DE VOS, P. et al. Encapsulation for preservation of functionality and targeted delivery of bioactive food components. International Dairy Journal, v. 20, n. 4 , p. 292-302, 2010.

DOUGLAS L. C.; SANDERS M. E. Probiotics and prebiotics in dietetics practice. Journal of the American dietetic association, v. 108, p. 510-521, 2008.

DUNNE, C. et al. In vitro selection criteria for probiotic bacteria of human origin: correlation with in vivo findings. American Journal of Clinical Nutrition, v. 73, p. 386-92, 2001.

FAO. Food and Agriculture Organization of the
United Nations. Guidelines for the Evaluation of Probiotics in Food. London, Ontario, Canada. April 30 and May 1, 2002.

FAVARO- TRINDADE, C. S. Revisão: Microencapsulação de ingredientes alimentícios. Brazilian Journal of Food Technology, v. 11, n. 2, p. 103-112, 2008.

FDA. Food, Drug Administration. Probiotics. New York, 2004. Disponível em: http://www.webdietitians.org/Public/GovernmentAffairs/92_adap1099. cfm. Acesso em: 06 de jan. de 2013.

GEORGE, M.; ABRAHAM, E. T. Polyionic hydrocolloids for the intestianal delivery of protein drugs: alginate and chitosan - a review. Journal of controlled release. v. 114, p.1-14, 2006.

GILL, H. S. Probiotics to enhance anti-infective defences in the gastrointestinal tract. Best Practice \& Research Clinical Gastroenterology, v. 17, n. 5, p. 755-773, 2003.

GOMES, C. R. et al. Influência de diferentes agentes de corpo nas características reológicas esensoriais de chocolates diet em sacarose e light em calorias. Ciência e Tecnologia de Alimentos Campinas, v. 27, n. 3, p. 614-623, 2007.

GODWARD, G.; KAILASAPATHY, K. Viability and survival of free and encapsulatedprobiotic bacteria in Cheddar cheese. Milchwissenschaft, v. 58, n. 11-12, p. 624-627, 2003a.

GODWARD, G.; KAILASAPATHY, K. Viability and survival of free, encapsulatedand co-encapsulated probiotic bacteria in ice cream. Milchwissenschaft, v. 58, n. 3-4, p. 161-164, 2003 b.

GODWARD, G.; KAILASAPATHY, K. Viability and survival of free, encapsulatedand co-encapsulated probiotic bacteria in yoghurt. Milchwissenschaft,v. 58, n. 7-8, p. 396-399, 2003c.

HEIDEBACH, T. et al. Microencapsulation of probiotic cell bymeans of rennet-gelation of milk proteins. Food Hydrocolloids, v. 23, p. 1670-1677, 2009.

JACKSON, L. S.; LEE, K. Microencapsulation and Food Industry. LWT - Food Science and Technology, v. 24, n. 4, p. 289-297, 1991.

KAILASAPATHY, K. Encapsulation technologies 
for functional foods and nutraceutical product development. CAB Reviews: Perspectives in Agriculture, Veterinary Science, Nutrition and Natural Resources, v. 4, n. 6, 2009.

KAILASAPATHY, K.; CHIN, J. C. Survival and therapeutic potential of probiotics organisms with reference to Lactobacillus acidophilus and Bifidobacterium spp. Immunology e Cell Biology, v.78, p.80-88, 2000.

KANMANI, P. et al. Effect of cryopreservation and microencapsulation of lactic acid bacterium Enterococcus faecium MC13 for long-term storage. Biochemical Engineering Journal, v. 58- 59, p.140- 147, 2011.

KRASAEKOOPT, W.; BHANDARI, B.; DEETH, H. Evaluation of encapsulationtechniques of probiotics for yoghurt. International Dairy Journal, v. 13, n. 1, p. 3-13, 2003.

LIU, X. D. et al. Characterization of structure and diffusion behaviour of ca-alginate beads prepared with external or internal calcium sources. Journal of microencapsulation, v. 19, n. 6, p. $775-782,2002$.

LIVNEY, Y. D. Milk proteins as vehicles for bioactives. Current Opinion in Colloid and Interface Science, v. 15, n. 1-2, p. 73-83, 2010.

MATTILA-SANDHOLM, T. et al. Technological challenges for future probiotic foods. International Dairy Journal, v.12, p. 173-182, 2002.

MENEZES, C. R. et al. Microencapsulação de probióticos: avanços e perspectivas. Ciência Rural, v. 43, n.7, p.1309-1316, 2013.

MORTAZAVIAN, A. M. et al. Principles and methods of microencapsulation of probiotic microorganisms. Iranian Journal of Biotechnology, v. 5, p. 1-18, 2007.

NAGPAL, R. et al. Potential of probiotic and prebiotics for synbiotic functional dairy foods: an overview. International Journal of Probiotics and Prebiotics, v. 2, p. 75-84, 2007.

NAZZARO, F. et al. Microencapsulation in food science and biotechnology. Current Opinion in Biotechnology, v. 23, p. 1-5, 2011.

OLIVEIRA, A. C. et al. Stability of microencapsu- lated B. lactis (BI 01) and L. acidophilus (LAC 4) by complex coacervation followed by spray drying. Journal of Microencapsulation, v. 24, n. 7, p. 685693, 2007.

OROSCO, I. M.; KUNIGK, C. J. Influência do preparo do inóculo na sobrevivência de bactérias probióticas encapsuladas liofilizadas. Instituto Mauá de Tecnologia, 2012.

PASIN, B. L.; AZÓN, C. G.; GARRIGA, A. M. Microencapsulación com alginato en alimentos. Técnicas y aplicaciones. Revista Venezolana de Ciencia y Tecnología de Alimentos, v. 3, n. 1, p. 130-151, 2012.

PREVOST, H.; DIVIES, C. Cream fermentation by a mixed culture of lactococci entrapped in two-layer calcium alginate gel beads. Biotechnol Lett, v. 14, p. 583-588, 1992.

REID, G. Probiotics and prebiotics - progress and challenges. International Dairy Journal, v. 18, p. 969-975, 2008.

SAIER, M. H.; MANSOUR, N. M. Probiotics and prebiotics in human health. Journal of Molecular Microbiology and Biotechnology, v. 10, p. 22-25, 2005.

SAJILATA, M. G.; SINGHAL, R. S.; KULKARNI, P. R. Resistant starch - a review. Comprehensive Reviews in Food Science and Food Safety, v. 5, n. 1, p. 1-17, 2006.

SHAH, N. P., RAVULA, R. R. Microencapsulation of probiotic bacteria and theirsurvival in frozen fermented dairy desserts. The Australian Journal of Dairy Technology, v. 55, n. 3, p. 139-144, 2000.

SHARP, M. D.; MCMAHON, D. J.; BROADBENT, J. R. Comparative evaluation of yogurtand low-fat Cheddar cheese as delivery media for probiotic Lactobacillus casei. Journal of Food Science, v. 73, n. 7, p. $375-377,2008$.

SHEU, T. Y.; MARSHALL, R. T. Microentrapment of lactobacilli in calcium aginate gels. Journal of Food Science, v. 54, n. 3, p. 557-561, 1993.

SIRÓ, I. et al. Functional food: Product development, marketing and consumer acceptance: A review. Appetite, v. 51, n. 3, p. 456-467, 2008. 
SUAVE, J. et al. Microencapsulação: Inovação em diferentes áreas. Revista Saúde e Ambiente / Health and Environment Journal, v. 7, n. 2, p. 12-20, 2006.

SUNNY-ROBERTS, E. O.; KNORR, D. The protective effect ofmonosodium glutamate on survival of Lactobacillus rhamnosus GG and Lactobacillus rhamnosus E-97800 (E800) strains during spray-drying and storage in trehalose-containing powders. International Dairy Journal, v. 19, p. 209-214, 2009.

THAMER, K. G.; PENNA, A. L. B. Caracterização de bebidas lácteas funcionais fermentadas

porprobióticos e acrescidas de prebiótico. Ciência e Tecnologia de Alimentos Campinas, v. 26, n. 3, p. 589-595, 2006.

VERGIN, F. Anti- und probiotika. Hippokratesv. 25, p.16-119, 1954. 